\title{
Study on the Sea-Buckthorn (Hippophae rhamnoides L.) Preparation Forms Destined to its Nutritio-Pharmaceutical Use
}

\author{
Carmen Georgeta DUMITRESCU* (MANOLE) \\ University of Agronomic Science and Veterinary Medicine, 59 Marasti, sector 1, 011464, Bucharest, \\ Romania; \\ * corresponding author: cdumitrescu68@yahoo.com \\ Bulletin UASVM series Agriculture 73(2)/2016 \\ Print ISSN 1843-5246; Electronic ISSN 1843-5386 \\ DOI 10.15835/buasvmcn-agr: 12420
}

\begin{abstract}
In conducting this research we started from the multiple uses of sea-buckthorn in our everyday life. In addition to the positive effect of sea-buckthorn plant on the environment, especially by fixing the soil, almost all parts of this miraculous shrub have therapeutically effect (fruits, leaves, shoots etc.) and can be consumed in various forms. Aim of this paper is to present the nutritional value of sea-buckthorn, recipes most frequently used and the effects that they have on people. In order to achieve all these, materials from the scientific literature were used, as well as an own research, carried out during a year, on a total number of 50 people. Results prove that the sea-buckthorn must be introduced, in greater extent, in our daily diet, as it improves human health.
\end{abstract}

Keywords: recipes, sea-buckthorn, therapeutic effects.

\section{INTRODUCTION}

Sea-buckthorn fruits, also named natural polyvitamins, are an extraordinary general tonic, which may be used fresh or preserved by freezing or drying. According to Brad et al. (2002) these are also astringent and they have vermifuges attributes, with results in the treatment of many and varied disorders. Sea-buckthorn is industrially or domestic processed in food purposes, as well as in medicinal ones (Mencinicopschi, 2004).

In this case, we started from the idea that the foods are, usually, natural nutritive complexes (food matrix) necessary to the body for the intake of substances, energy, information. In the same time, they are able to sustain life and to simultaneously respond to some subjective requirements (hunger, pleasure etc.), to some customs, traditions, possessing a symbolical significance (Pop, 2013).

Starting from a few recipes collected from various sources and using the results of other renowned researchers in the field, the paper aims to establish the accurate nutritional and therapeutical value of sea-buckthorn fruits, leaves, shoots and of the whole plant. Were also take into consideration the ways of their use in multiples forms have been pursued - for food, medical purposes, but also in environmental protection, especially relating to the soil restoration.

\section{MATERIALS AND METHODS}

The study material was represented by natural products obtained from sea buckthorn (Hippophae rhamnoides L.) being well known that the fruits of this plant have a high content of (also see Tab. 1):

- Vitamin E (alpha-tocopherol), Vitamin C (ascorbic acid), Vitamin B2 (riboflavin), Vitamin B3 (nicotinamide),Vitamin H (biotin);

- alpha, beta and gamma carotenes;

- flavonoids;

- polyphenols;

- Potassium (K), Zinc (Zn), Selenium (Se); 
- serotonin;

- many acids (oleic, linoleic, palmitic, palmitoleic, lauric acid) etc.

Taking care on the fact that the daily diet shoud be based on the food that hide in them the health and delay aging "secret" (Proorocu, 2006) such as those listed above, through nourishment we can offer to our body the chance to maintain or rebuild its balance.

In the the experiments performed for this paper were used a few classic recipes (of syrup, juice, sea-buckthorn oil, sea-buckthorn honey) which have been tested on consumers who agreed to follow a long-term treatment. The survey was conducted with a total of 50 persons with various diseases, and they were contacted every 3 months in order to see their evolution during the applied treatment.

At the beginning, all those 50 people completed a questionnaire, which consisted in 10 questions with simple answer, "yes" or "no"

Questions from the questionnaire:
1. To improve your health condition, you also used herbal products besides the pharmaceutical ones?

2. Among the herbal products used are included those with sea-buckthorn?

3. Do you or did you used sea-buckthorn honey?

4. Do you or did you used sea-buckthorn oil?

5. Do you or did you used sea-buckthorn syrup?

6. Do you or did you used sea-buckthorn juice?

7. As a result of the sea-buckthorn use, did you noticed any improved in your health condition?

8. Do you prepare yourself products based on sea-buckthorn in traditional way, in your own household?

9. Do you trust in the miraculous power of seabuckthorn for health?

10. Would you like to participate in a research study, whict consists in introducing seabuckthorn prepared in various forms in your diet, for a specific period (one year)?

Following the initial evaluation, it appeared

Tab. 1. The main component materials of sea-buckthorn fruit (Proorocu, 2006)

\begin{tabular}{lcc}
\hline Components & Unit of measure (U.M.) & Value \\
\hline Oil from seeds & & 2 \\
\hline Oil from pulp & & 2 \\
\hline Matter from pressing the seed & & 5 \\
\hline Insoluble matter & & 3 \\
\hline Fruit acid & & 3 \\
\hline Carbohydrates & & 3 \\
\hline
\end{tabular}

Tab. 2. Composition of sea-buckthorn fresh fruit - average content of the main bioactive compounds in $100 \mathrm{~g}$ fruit (***www.cttecotech.ro)

\begin{tabular}{lccc}
\hline $\begin{array}{l}\text { Crt. } \\
\text { No. }\end{array}$ & Bioactive compounds & U.M. & Content \\
\hline 1. & Vitamin C & $\mathrm{mg}$ & $200-1500$ (tipically 600) \\
\hline 2. & Vitamin E (mix of tocopherols) & $\mathrm{mg}$ & $\leq 180$ \\
\hline 3. & Folic acid & $\mu \mathrm{g}$ & $\leq 80$ \\
\hline 4. & Carotenoids ( $\beta$-carotene, lycopene, zeaxanthin) & & $30-40 \mathrm{mg}$ \\
\hline 5. & Unsaturated fatty acids (oleic, palmitic, linolenic & $\%-11 \%$ & acid) \\
\hline 6. & Organic acids (enolic, citric, tartaric acid) & $\%$ & $\begin{array}{c}\text { (3-5\% in fruit pulp and 8-18\% in } \\
\text { seeds) }\end{array}$ \\
\hline 7. & Flavonoizi & $\mathrm{mg}$ & pH of juice: $2.7-3.3$ \\
\hline
\end{tabular}


that out of the 50 people surveyed, 42 had also used herbal products for improving their health condition, in addition to pharmaceuticals. Of these, 29 subjects had used sea-buckthorn as honey with sea-buckthorn and syrup, 7 people used seabuckthorn oil and 6 people sea-buckthorn juice.

As a result of these preparations use, 34 respondents claim to have observed, in time, an improvement in their own health condition. All 50 people questioned wanted to participate to the research study.

\section{RESULTS AND DISCUSSION}

From old times, in the Romanian households sea-buckthorn is prepared both for food and medicinal purposes in various forms: juice, syrup, jam, marmalade, wine and liquor, tea, oil and other products. The value of the species, which is also known as "Virgin Mary's remedy beans", is uncontested. It is found in many recipes that we gathered during our research, of which most frequently prepared and used are: the syrup, the juice, the oil, the honey with sea-buckthorn.

Results obtained during the research are expressed as informative and justificative indicators, constituting the required basis in order to demonstrate that, unlike other plants, sea-buckthorn is a valuable plant also because it can be fully exploited by fruits, leaves and roots. The most valuable product obtained from seabuckthorn fruits, but which is more difficult to be extracted by conventional means, is the seabuckthorn oil, which in the specialty literature is known as (Mencinicopschi, 2004):<=d provides trophicity of the hepatic cell;

? immunomodulator, has synergistic action with the $\alpha$ interferon and, in particular, contributes to the synthesis of proteins - raw material for the interferons;

[. coronary protector;

[? antiatherosclerotic;

[? product that slows down the aging process by consuming unwanted free radicals;

2] preventing the cancer through its high content in $\beta$-carotene;

? a good cicatrizing (externally managed), with a remarkable anti-inflammatory and nutritive effect;

? an excellent protector against solar or any other radiation.

In the literature there are evidence that the sea-buckthorn oil is an important remedy in the treatment of many skin affections, being also demonstrated that the use of sea-buckthorn oil exceeds the cosmetic products particularities.

Sea-buckthorn oil can be easily prepared at home, using fresh sea-buckthorn fruit and sunflower or olive oil (preferably cold-pressed, extravirgin) in equal quantities. Sea-buckthorn fruits must be crushed and placed in a jar, with the oil. The jar shall be kept at the room temperature for at least three weeks, being shaked daily. After this period, the fruits will be crushed again and put back in the jar, this time for only two days, while the jar has to stay in a warm or sunny place. In the end, the clear oil from above the jar can be drained into another glass container and stored in the refrigerator or in a cool and dark place. Another traditional recipe says that you need $250 \mathrm{~g}$ dried and grounded sea-buckthorn and $500 \mathrm{ml}$ olive oil cold-pressed, extravirgin. Preparation: in an one liter bottle are put the sea-buckthorn fruit and the

Tab. 3. Composition of sea-buckthorn oil - proportions evaluated for $100 \mathrm{~g}$ of each product ${ }^{* * *}$ www.cttecotech.ro)

\begin{tabular}{|c|c|c|c|c|c|}
\hline $\begin{array}{l}\text { Crt. } \\
\text { No. }\end{array}$ & Bioactiv compound & U.M. & Seed oil & Fruit juice oil & Fruit residue oil \\
\hline 1. & Vitamin E & \multirow{6}{*}{$\mathrm{mg} / 100 \mathrm{~g}$} & 207 & 171 & $300-600$ \\
\hline 2. & Vitamin K & & $110-230$ & $54-59$ & - \\
\hline 3. & Carotenoids & & $30-250$ & $300-870$ & $1280-1860$ \\
\hline 4. & Total acidity & & 11 & 38 & - \\
\hline 5. & Total flavonoids & & - & - & 550 \\
\hline 6. & Total sterols & & 1054 & 721 & - \\
\hline 7. & Unsaturated fatty acids & \multirow{2}{*}{$\%$} & 87 & 67 & 70 \\
\hline 8. & Saturated fatty acids & & 13 & 33 & 30 \\
\hline
\end{tabular}


Tab. 4. The content in minerals of the sea-buckthorn fruits and of the juice obtained from sea-buckthorn fruits ( ${ }^{* * *}$ www.cttecotech.ro)

\begin{tabular}{ccc}
\hline Minerals & Fruit content $[\mathrm{mg} / \mathrm{kg}]$ & Juice content $[\mathrm{mg} / \mathrm{l}]$ \\
\hline Potasium & $6.44-22$ & $147-209$ \\
\hline Calcium & $0.8-1.48$ & $64-256$ \\
\hline Magnesium & $0.47-73$ & $53.3-165$ \\
\hline Iron & $22-33$ & $4.13-10.9$ \\
\hline Selenium & 5.02 & $7.96-11.3$ \\
\hline Zinc & $8.8-27$ & $2.09-6.31$ \\
\hline Manganese & $8.7-15$ & $0.81-3.86$ \\
\hline
\end{tabular}

olive oil, it is stoppered and left for two weeks in a warm place. The bottle should be shaken each day, al least once. After two weeks, the oil thus obtained is filtered through a thick sieve or a double piece of gauze, poured into smaller and brown bottles, and kept in a dry, dark and cool place. Content of the main bioactive compounds found in the lipid extract (sea-buckthorn oil) obtained from seeds, fruit pulp (juice) and pulp residue (remaining after juice extraction) is shown in Tab. 3 .

With a composition rich in antioxidants, seabuckthorn oil bring important benefits for skin and body cells, being one of the most effective natural products that can be used to maintain the beauty. It is rich omega fatty acids, with a crucial role for a healthy skin, strong nails, shiny and smooth hair.

Among the the benefits that anyone can enjoy using sea-buckthorn oil, we mention:

? smooth and hydrated skin;

[? a high energy level;

? a strong immune system;

? fewer wrinkles;

2] rich, shiny and revitalized hair (without looking fragile or damaged).

After making some research, it was found that the sea-buckthorn oil also has other positive effects for the human body. Rich in antioxidants, this type of oil can improve the general health condition of a person by improving the problems, from cardiovascular to nervous system diseases.

Another traditional product very easy to prepare and with strong beneficial effects is the honey with sea-buckthorn. Preparation: seabuckthorn is cleaned of stalks and impurities, is washed in a sieve under running cold water, and it is put a clean kitchen towel and dried well. Sea-buckthorn fruits are put in a jar and honey is poured over them. The proportion sea-buckthorn - honey can vary between $1 / 1$ and up to $3 / 4,1 / 4$.

The next step is to homogenize well with a wooden spoon, crushing the grains of seabuckthorn. Is left to macerate for 7-10 days in the refrigerator, while it is mixed at regular intervals. Is must be consumed every morning one teaspoon, on the empty stomach, being well chewed before swallowing it. It may be stored up to 12 months in a refrigerator.

Sea-buckthorn syrup - is obtained one liter of sea-buckthorn juice through the squeezing of 2 kilos of sea-buckthorn fruit, very rich in minerals (Tab. 4). The juice is combined with one kilo of honey in a vessel and it is left for 4 - 5 days in a cold place, being periodically stirred with a wooden spoon. From this syrup can be taken one teaspoon in every morning, but also on the empty stomach, before eating.

Tonic wine. Preparation: over $200 \mathrm{~g}$ of dried fruit are poured 5 liters of boiled and cooled water, 1.5 kilos of sugar and a cube of brewers yeast. This mixture is left to ferment from 15 to 20 days, with a fermentation tube, shaking the jar occasionally. Is left to decant before being dragged into bottles. The final product is an easy alcoholized drink, having pineapple flavor.

Besides its recognized quality of best natural fortifier of the immune system, the sea-buckthorn has the capacity to treat and aid in curing many diseases.

Recipes based on sea-buckthorn presented so far have led to concrete results in terms of the health of persons who have agreed to participate in the study. All these preparations are known and widely used by the population, so it was no risk in introducing them into the diet. At the 


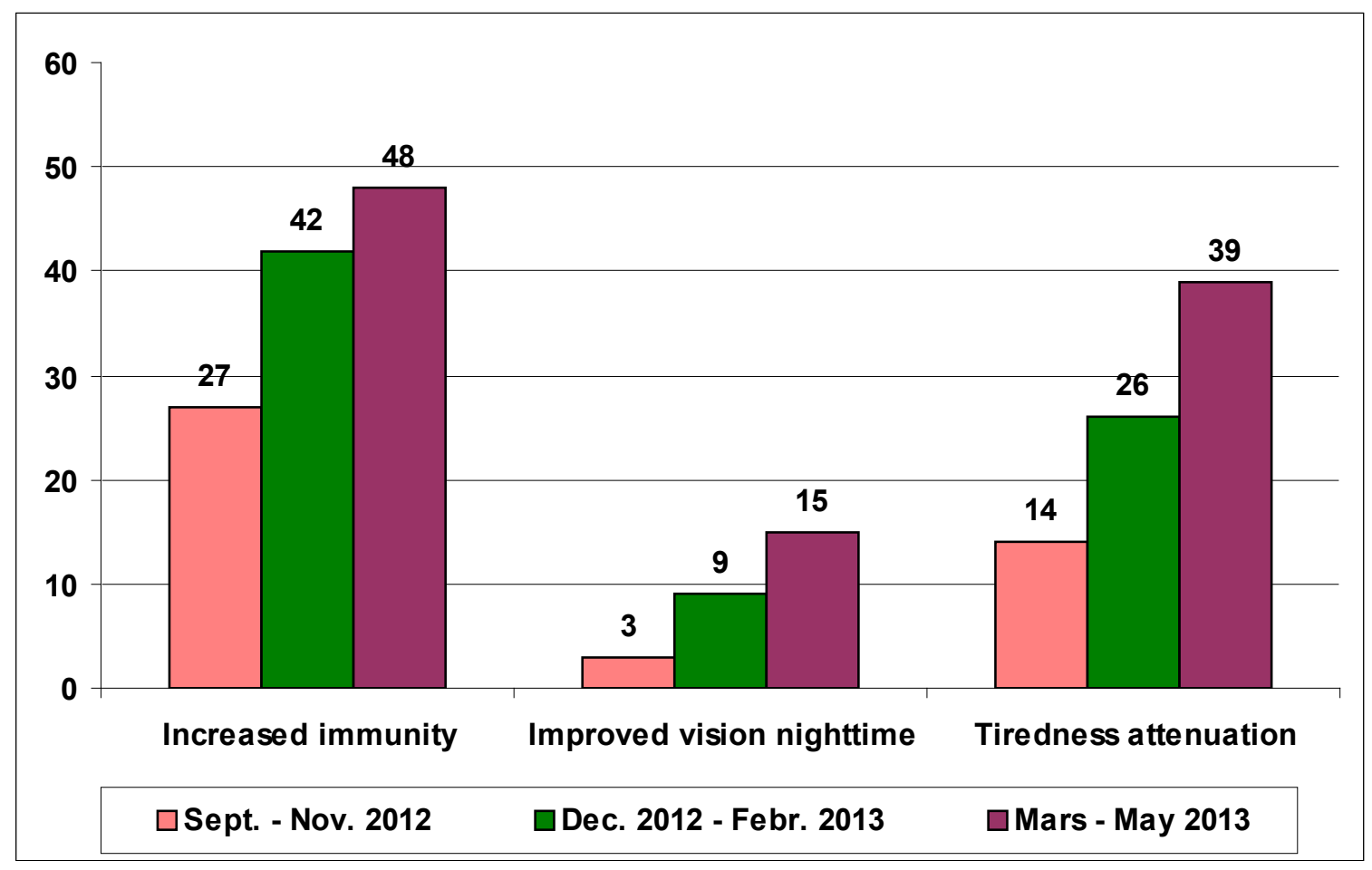

Fig. 1. Influence of the sea-buckthorn based products on the health of the 50 people who participated in the research study (original)

beginning of this research all 50 people performed a set of general analysis. Thus, it was observed that, without making any other change in their regular way of life, by simply using preparations based on sea-buckthorn, the people registered positive results regarding their health condition (Fig. 1). The analyzes made periodically by each person showed that some problems have been ameliorated, while the quantity of vitamins and nutrients from the organism gradually increased. All these will be discussed in detail in a subsequent scientific paper.

Therefore, after performing evaluations every 3 months during the period September 2012 May 2013, were noted the following: since the first evaluation of the treatment 27 of the participants actually noticed an increase in their immunity, a fact observed due to the low frequency of respiratory virus diseases contacted during the cold season. At the second assessment 42 people found the same thing, while in the end 48 out of 50 persons answered affirmative concerning the increasing of the immunity.

Another parameter taken into consideration was the nighttime vision, for which, after 9 months from the beginning of the study, 15 people who had difficulties in this area reported an improvement in their deficiency.

Also progressive has been factor attenuation of tiredness of the body, which found positive for 14 (first evaluation), 26 (second evaluation) and 39 subjects at the end third stage of the evaluation. There are three more months to evaluate in order to complete the study year proposed and to have a complete analysis.

\section{CONCLUSION}

1. Sea-buckthorn fruit has a great significance in the human diet, being rightly called as natural polivitamin. Seabuckthorn is a valuable plant by the fact that, unlike other plants, it can be used in fully through its fruits, leaves and roots. The whole plant is medicinal, but it has the most active substances in fruits.

2. A concrete result is that the sea-buckthorn recipes and preparations have a beneficial effect on the human body. From the total of 50 people monitored, 48 felt better after the introduction of sea-buckthorn in their diet. 
3. It can be said that we can keep our health with the miraculous and undisputed help of the oldest pharmacist in the world - the nature, both represented by the wild and by the cultivated plants.

\section{REFERENCES}

4. Brad I (2002). Catina alba, o farmacie intr-o planta, Ed Tehnica, Bucuresti.

5. Mencinicopschi G (2004). Alimentul, matricea alimentară, Revista Stiinta si Tehnica, 3:16-22.
6. Pop OI (2013). Efecte fiziologice si terapeutice ale unor antioxidanti naturali nutritionali si nenutritionali, UMF Cluj- Napoca, Teza de doctorat.

7. Proorocu A (2006). Cercetari privind importanța catinei albe (Hippophae rhamnoides L.) pentru protectia mediului si ca resursa in economia sanatatii umane, USAMV Bucuresti, Teza de doctorat.

8. ${ }^{* * *}$ www.cttecotech.ro 